\title{
CHANGING HEALTH RESOURCE DEMANDS FOR INJURY DUE TO FALLS IN AN AGEING POPULATION
}

Jerry Moller

New Directions in Health and Safety

The population of New South Wales is ageing. Over the next 50 years low fertility rates, relatively low rates of inmigration of younger people, and the ageing of the post World War II 'baby boom' generation, will significantly increase the proportion of the population aged over 65 . For many diseases, older people use health resources at a higher rate than younger people. Combined with the anticipated demographic shift, we can expect that this will increase the demand for health services rapidly over this period. This article considers the impact of these demographic changes on resources related to the treatment and rehabilitation of injury, which will be required if both current rates of incidence and treatment patterns continue over the next 50 years. In particular, the impact of population ageing on resources that are required for the treatment of injury due to falls is examined. The agespecific distribution of falls injury shows that both the incidence and severity increases rapidly in the older population. This, combined with the extended life expectancy of women, will result in a large increase in the resources required for the treatment of fall related injury, unless there is a reduction in the incidence, their severity, and/or the resources required to treat each case.

\section{METHODS}

The projected estimated incidence and cost of a range of causes of injury has been calculated using Australian
Bureau of Statistics (ABS) population projections to 2051 in conjunction with resource utilisation and cost estimates from the Australian Institute of Health and Welfare. ${ }^{1,2}$ Estimates have been made for each of the three ABS projection series (known as Series I, II, and III), each of which are based on differing assumptions about fertility, mortality, and migration.

The assumptions made in the calculations are that the NSW age-specific rates of injury and the resources used to treat these injuries will remain unchanged and will follow the patterns described for the Australian population by Mathers, ${ }^{3}$ and for the NSW population by Moller. ${ }^{4}$ Therefore, trends shown in the results presented can be attributed solely to the changing demography of NSW.

Cost estimates are based on the health system costs only. ${ }^{3}$ These are the recurrent health care costs that occur in one year apportioned according to cause. The cost estimates represent the cost to government of each cause of injury, but do not identify the total annual economic cost of each cause.

\section{RESULTS}

This article focuses on the resource implications of injury due to falls because, of all causes of injury, they show the most rapidly rising trend. Other causes of injury have been addressed in the full report developed for the Injury Prevention and Policy Unit of the NSW Department of Health. ${ }^{4}$ In order to present the broad implications of injury due to falls, results will be presented for:

\section{FIGURE 1}

PROJECTED UTILISATION OF PUBLIC HOSPITAL BED DAYS RESULTING FROM FALLS, NSW, 1993-2051 USING ABS SERIES I POPULATION PROJECTIONS

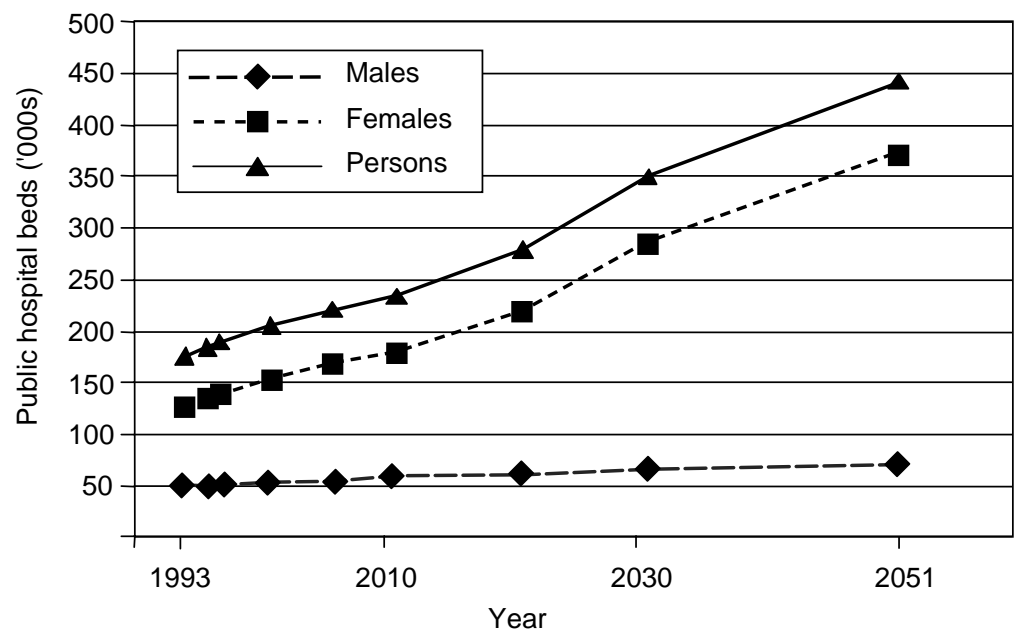


- public hospital bed days;

- nursing home places;

- total health system costs.

Comparison of the effect of different population projection series are presented only for public hospital bed days, as the patterns here are replicated in other resource areas. All other results will be based on ABS Series I, which predicts the lowest overall growth and the greatest demographic change for the period. Readers wishing information analyses using other projection series should contact the Injury Prevention and Policy Unit of the NSW Department of Health.

\section{Public hospital bed days}

Figure 1 shows that fall injuries will rise sharply over the next 50 years. The major component of the rise is among the female population, as women form an increasing proportion of the total population as they age, due to the earlier mortality of men.

\section{Nursing home places}

Different types of injuries produce different demands for nursing home places. Nursing home places are required where the injury is severe and disabling and where overall frailty determines the need for high levels of care. For both road traffic injury and self-harm, the effect on nursing

\section{FIGURE 2}

PROJECTED UTILISATION OF NURSING HOME PLACES RESULTING FROM FALLS, NSW, 1993-2051

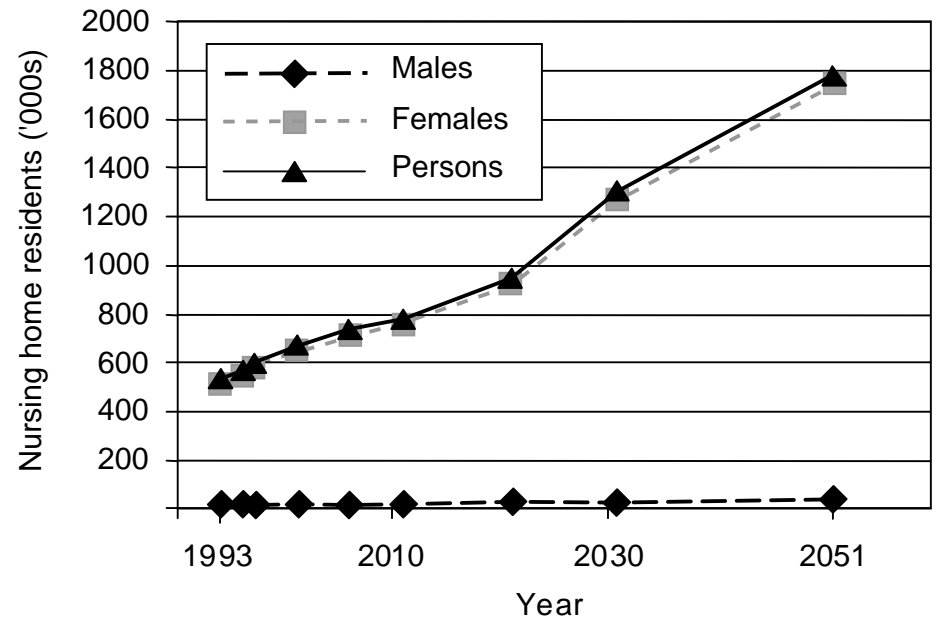

\section{FIGURE 3}

PROJECTED COSTS TO THE HEALTH SYSTEM FROM FALLS, NSW, 1993-2051

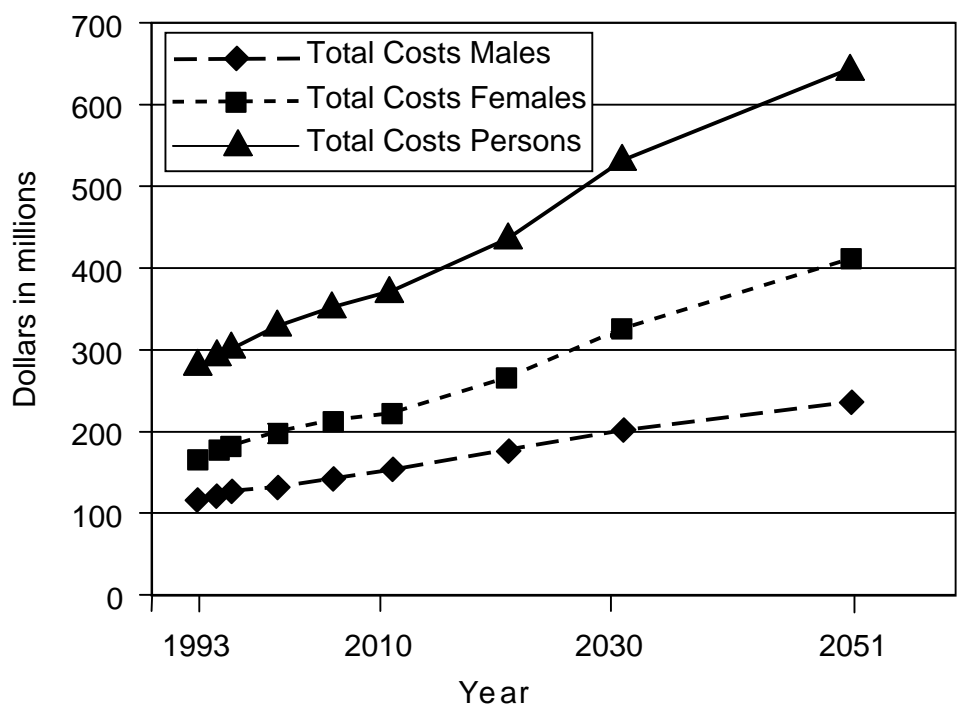




\section{FIGURE 4}

INFLUENCE OF AGE AND SEX ON PROJECTED DEMAND FOR PUBLIC HOSPITAL BED DAYS, BASED ON ABS SERIES I POPULATION PROJECTIONS, NSW, 1994-2051

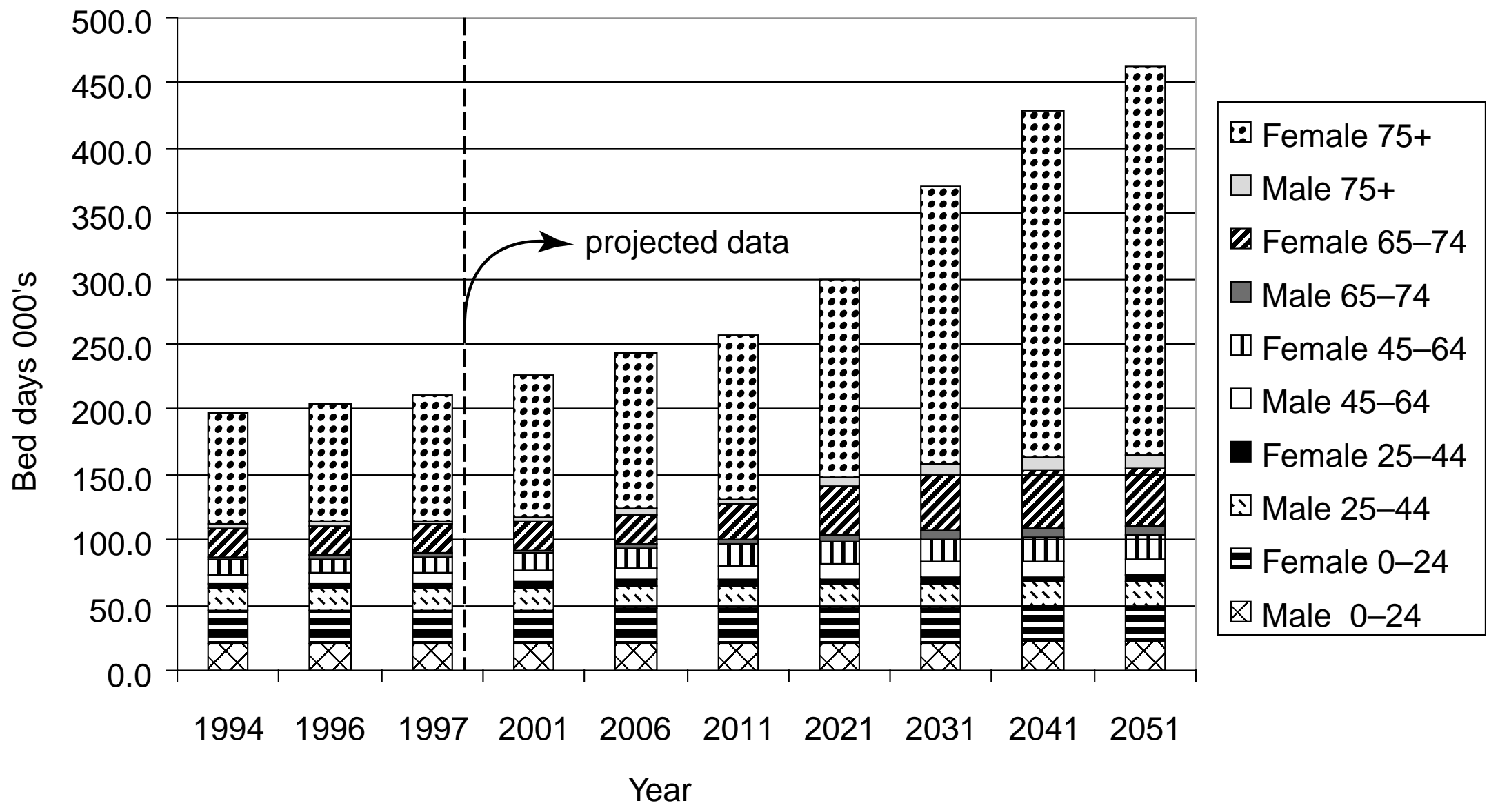


home placement of an injury is almost gender neutral. This reflects the higher incidence occurring in younger people and the predominance of males in younger age groups offsetting the demand created by the larger older female population experiencing falls.

The picture for falls however is quite different. Figure 2 shows how it is women who drive the steep projected rise in demand for nursing home places. The combination of an increasing proportion of women in the elderly population, a higher incidence of disabling falls among older women, and the ageing effect, results in a very steep projected trend in the demand for nursing home beds related to fall injury (Figure 2).

\section{Total health system costs}

Mathers's estimates of overall health system cost have been used to determine the impact of the demographic shift on the costs of road traffic injury, injury due to selfharm, and injury due to falls. Analysis indicated that fall injury costs are more expensive than those for road injury and will rise at a much higher rate, increasing by almost double over the 50-year period as a result of the demographic shift (Figure 3).

\section{The increasing proportion of women in the elderly population}

One of the major features of the data describing injury due to falls is the influence of the increasing proportion of elderly women in the NSW population. This effect is best examined by considering the projected age and sexspecific demand for bed days.

Figure 4 demonstrates that the major contributor to the increased demand for bed days is women over the age of 75 years. Women 65 to 75 years of age also have some affect. Apart from these two groups, there is little trend in demand projected over the period.

\section{DISCUSSION}

The effect of demographic changes on the resources required to treat injury resulting from falls is significant. In the first 50 years of this century, the resources required can be expected to at least double if there is no change in the current incidence rate, severity or treatment patterns. The major increase in demand will come from women aged 75 years or more. The total additional number of bed days required equates to 800 additional hospital beds (that is, four 200-bed hospitals) and there will be a need for 1,200 additional nursing home places.

If this potential burden is to be reduced, a broad public health strategy that seeks to reduce the incidence, severity and treatment costs of fall injuries is required. Strategies to prevent falling and prevent or reduce the severity of fall injuries must be developed. More effective treatment, especially treatment for injuries that lead to disability and high dependency care is required. Also alternative systems of care other than nursing homes need to be explored for elderly women.

More needs to be known about the effectiveness of primary prevention for falls and whether strategies targeting fall prevention or fall injury prevention or a mix of these two is needed. A number of preventive interventions have been shown to be effective, for example gentle exercise, ${ }^{5}$ and environmental change, in reducing falls and fall injury.

Further work is also needed to systematically assess and manage risk to the individual within the elderly population. Most of the current activity is a result of individual clinical assessment proximate to the time of risk. Unfortunately there is a paucity of evidence of effective interventions among the frail elderly. A longterm public health approach that targets both men and women, but in particular all women who will reach the age of 75 during the next 50 years is required.

However, while the problem emerges among the elderly it originates in patterns of exercise and diet in earlier years, which then interact with both the environments in which the elderly live and the processes of ageing. While the current approaches to falls risk management focus on those at immediate risk, a problem of this magnitude requires a systematic and multifaceted approach across the lifespan. Indeed, we need to ensure that the increase in demand for treatment does not reduce resources for prevention, as failure to fund prevention will lead to resource demands for treatment that will be difficult to meet. As treatment costs rise it will be difficult to find resources for prevention and the cycle of increased demand will be accelerated. A policy for the prevention of falls in older people, being developed by the NSW Department of Health, is a direct response to these future resource implications for the health system.

\section{REFERENCES}

1. Australian Bureau of Statistics. Australian Bureau of Statistics Population Projections 1997-2051. Canberra: Australian Bureau of Statistics, 1998. Catalogue no. 3222.0.

2. Mather C and Penm R. Health System costs of injury, poisoning and musculo-skeletal disorders in Australia 1993-94. Canberra: Australian Institute of Health and Welfare, 1999.

3. Mathers C, Penm R, Carter R, Stevenson C. Health system cost of diseases and injury in Australia 1993-94. Canberra: Australian Institute of Health and Welfare, 1998.

4. Moller J. Estimated cost of injury (\$millions) by cause, NSW 1995-96. Sydney: NSW Department of Health, Injury Prevention and Policy Unit, 1998.

5. Lord S, Ward J, Williams P, and Strudwick M. The effect of a 12 month exercise trial on balance, strength and falls in older women: a randomised controlled trial. J Am Geriatr Soc 1995; 43: 1198-206. 鍳 